\title{
Review Article \\ Role of the Microbiota and Antibiotics in Primary Sclerosing Cholangitis
}

\author{
James H. Tabibian, ${ }^{1}$ Jayant A. Talwalkar, ${ }^{1}$ and Keith D. Lindor ${ }^{2}$ \\ ${ }^{1}$ Division of Gastroenterology and Hepatology, Mayo Clinic, 200 First Sreet SW, Rochester, MN 55905, USA \\ ${ }^{2}$ Executive Vice Provost \& Dean, College of Health Solutions, Arizona State University, 550 North 3rd Street, \\ Phoenix, AZ 85004, USA
}

Correspondence should be addressed to Keith D. Lindor; keith.lindor@asu.edu

Received 1 May 2013; Accepted 5 September 2013

Academic Editor: Jaime Aranda-Michel

Copyright (C) 2013 James H. Tabibian et al. This is an open access article distributed under the Creative Commons Attribution License, which permits unrestricted use, distribution, and reproduction in any medium, provided the original work is properly cited.

Primary sclerosing cholangitis (PSC) is an idiopathic, progressive, cholestatic liver disease with considerable morbidity and mortality and no established pharmacotherapy. In addition to the long-recognized association between PSC and inflammatory bowel disease, several lines of preclinical and clinical evidence implicate the microbiota in the etiopathogenesis of PSC. Here we provide a concise review of these data which, taken together, support further investigation of the role of the microbiota and antibiotics in PSC as potential avenues toward elucidating safe and effective pharmacotherapy for patients afflicted by this illness.

\section{Introduction}

Primary sclerosing cholangitis (PSC) is a chronic, fibroinflammatory, cholestatic liver disease of unknown etiopathogenesis that affects children and adults worldwide [1-3]. PSC leads to end-stage cirrhosis, represents a major risk factor for cholangiocarcinoma (CCA), and carries a median liver transplant- (LT-) free survival of approximately 12 years [4-6]. Despite clinical trials of over fourteen different pharmacologic agents, including but not limited to various immunosuppressants and antifibrotics, medical therapy for PSC has yet to be established [2]. Unlike in other cholestatic liver diseases (e.g., primary biliary cirrhosis), treatment with ursodeoxycholic acid (UDCA) has not been clearly shown to have a beneficial effect in PSC [7]. In addition, high doses of UDCA may be associated with significantly greater incidence of adverse outcomes [8]. Due to its progressive, idiopathic nature and lack of medical therapy, PSC remains a leading indication for liver transplantation in northern Europe and the United States despite its relatively low prevalence (0.5-1.5 per 10,000) $[9,10]$. Although operative treatment with liver transplantation (LT) is effective for PSC, it is only performed in specialty centers and in select patients; furthermore, even in suitable LT candidates, PSC and CCA can recur post-LT
[11-13]. Therefore, given the morbidity and mortality of PSC and the challenges associated with operative treatment, safe and effective pharmacotherapies are critically needed.

PSC is now generally accepted as being a heterogeneous, pathogenically complex disease, with genetic, immunologic, environmental, and other potential factors being involved $[2,14]$. There are now several lines of evidence suggesting that one such important and ostensibly modifiable etiopathogenic factor is the microbiota, particularly enteric bacteria. Here we provide a concise review on the molecular/cellular, translational, and clinical data regarding the possible role of the microbiota in the pathogenesis of PSC and as a target of pharmacologic therapy for patients afflicted with this disease.

\section{Primer on the Relationship between PSC and the Gut}

The association between PSC and the gut, most notably inflammatory bowel disease (IBD), was first reported over four decades ago $[15,16]$. The geoepidemiology of IBD among patients with PSC is heterogeneous; for example, an estimated $75 \%$ of Western patients with PSC are (or become) codiagnosed IBD (the majority of whom have 


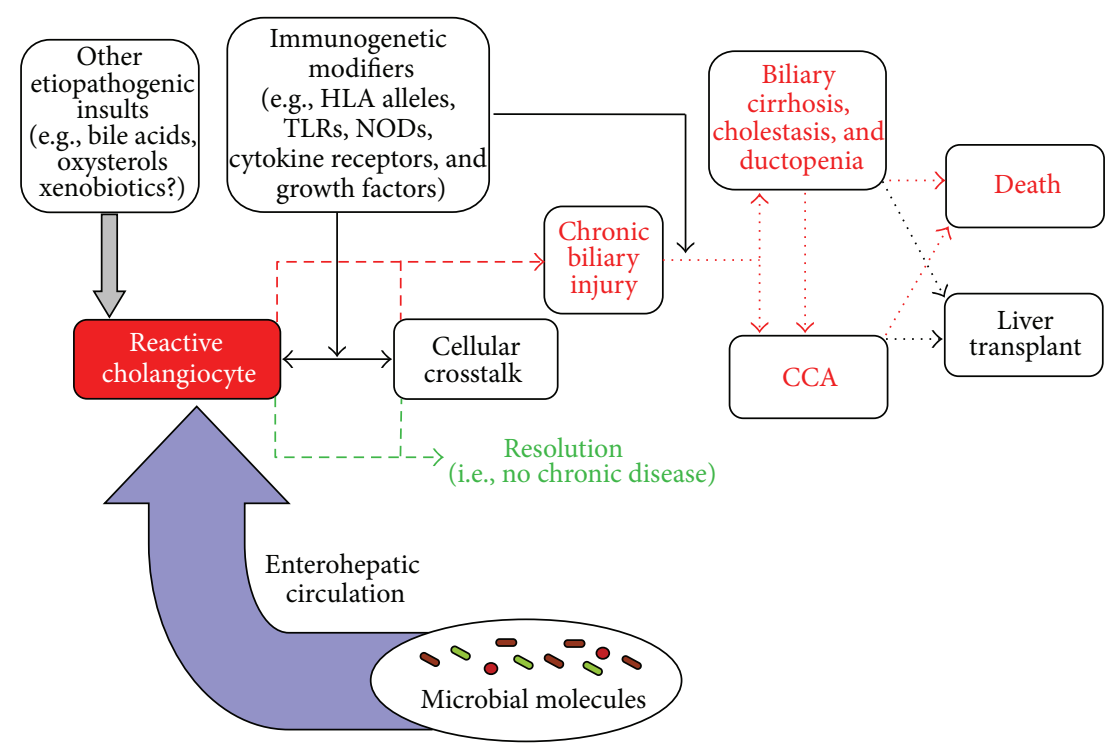

FIGURE 1: Proposed conceptual model of primary sclerosing cholangitis (PSC) etiopathogenesis. Cholangiocytes exist in a microenvironment abundant in potential etiologic mediators of cellular insult and activation, including microbial as well as nonmicrobial molecules. Whether PSC etiopathogenesis is related to increased exposure to constitutive molecular mediators of injury (e.g., through the enterohepatic circulation), alterations in the types of these mediators (e.g., due to enteric microbial dysbiosis), and/or an aberrant resident (e.g., cholangiocyte, hepatocyte) or recruited (e.g., lymphocyte) hepatic cell response remains uncertain. Immunogenetic factors can modify these variables and thus play a role in modulating initiation and progression of biliary injury in PSC. CCA: cholangiocarcinoma; HLA: human leukocyte antigen; NOD: nucleotide-binding oligomerization domain receptor; TLR: toll-like receptor.

ulcerative colitis, UC) $[1,17]$ as compared to only $23 \%$ in some cohorts of Japanese patients [18]. The PSC-IBD association is thought to be related at least in part to the increased intestinal permeability observed in some patients with IBD [19-21] as well as the direct anatomic link between the gut and the liver, that is, the enterohepatic circulation $[14,22]$. Although the putative gut-derived trigger(s) of hepatobiliary pathobiology in PSC has not been determined, microbial metabolites or products (i.e., pathogen-associated molecular patterns, PAMPs) such as lipopolysaccharide (i.e., endotoxin, LPS) and peptidoglycan (i.e., a bacterial cell wall polymer, PG) have been proposed as likely candidates [23, 24]. This forms the basis of what has been referred to as the "leaky gut" or "PSC microbiota" hypotheses (the latter not emphasizing a need for increased intestinal permeability given some patients with PSC who have no detectable bowel disease and normal intestinal permeability) $[23,25,26]$. Indeed, portal bacteremia and bacteriobilia have both been described in patients with PSC-IBD $[27,28]$. However, the extent to which the association between PSC and IBD is due to (i) increased enterohepatic circulation of PAMPs, (ii) abnormal PAMPs (e.g., as a result of enteric microbial dysbiosis, as seen in IBD) [29-31], or (iii) an aberrant or hyperreactive cholangiocyte and/or innate immune response (i.e., as a result of "immunogenetic susceptibility" $[24,32,33])$ to essentially normal levels and repertoires of enterohepatically circulated PAMPs (or other potential gut-derived molecules) remains a key unknown; given the heterogeneity of PSC, it is possible that any of these three possibilities may be operative in a given patient (Figure 1) [2, 24].

\section{Findings from Animal Models Supporting the Gut-Hepatobiliary Disease Relationship}

Several lines of experimental evidence from animal models demonstrate that enteric dysbiosis and/or administration of bacterial antigens can lead to hepatobiliary inflammation with various features of PSC. Lichtman et al. were the first to conduct a number of elegant studies in the early 1990s demonstrating this relationship. For example, rats with small bowel bacterial overgrowth as a result of surgically created self-filling jejunal blind loops were found to have abnormalities of the extrahepatic and intrahepatic bile ducts that resembled PSC both histologically and cholangiographically, similar to the abnormalities found in the multidrug resistant 3 (mdr2) knockout mouse [44] (currently among the most widely-utilized murine models of PSC) [45]. Interestingly, treatment of these rats with mutanolysin, an enzyme which breaks the $\beta 1-4$ linkage of $\mathrm{N}$-acetylmuramyl acid and $\mathrm{N}$ acetylglucosamine inherent to PG, but not with UDCA, prednisone, methotrexate, or cyclosporin $\mathrm{A}$, resulted in a significant decrease in plasma aspartate aminotransferase and liver histology scores [46]. Extending these findings, a subsequent study showed that intraperitoneal injection of rats with PG resulted in (micro)cholangiographic irregularities of smaller intrahepatic bile ducts and larger ductules, focal areas of narrowing and fusiform sacculations, and histologic evidence of bile duct destruction [47]. Another group found that rectal administration of $\mathrm{N}$-formyl L-methionine L-leucine L-tyrosine, a chemotactic peptide produced by $E$. coli which, after entering the enterohepatic circulation, 
is secreted into bile by hepatocytes, resulted in a mixed inflammatory hepatobiliary infiltrate with predominantly small duct cholangitis [48].

In a more recent study, it was demonstrated that repeated inoculation of Balb/c mice with $S$. intermedius resulted in nonsuppurative cholangitis and production of antibiliary epithelial cell and antinuclear antibodies, as seen in a considerable proportion of patients with PSC $[49,50]$. In addition to the animal models described above, several other infectious models, including but not limited to C. parvum-inoculated mice, demonstrate at least some biochemical, histologic, and/or cholangiographic features of PSC, as reviewed in more detail elsewhere [51].

Although these models (and for that matter, no toxininduced, knockout, or other model) do not specifically recapitulate the entirety of findings characteristic of PSC, they do provide a premise which supports the notion that hepatobiliary disease in PSC may be modified, if not caused, by aberrant microbial molecule-host interactions. This premise, together with clinical or human cell line observations, as will be reviewed below, has provided impetus for a growing number of clinical studies of antibiotics in patients with PSC.

\section{Human Tissue-Based Translational Studies Supporting the PSC Microbiota Hypothesis}

Given that PAMPs such as LPS, PG, and other microbially derived molecules (e.g., lipoteichoic acid) have been proposed as possible contributors or drivers of hepatobiliary pathobiology in PSC, it is noteworthy to highlight the body of evidence that PAMPs can be directly detected by and induce signal transduction in cholangiocytes [24, 52-56]. Indeed, cholangiocytes are immunologically active cells that express pathogen recognition receptors, including nucleotide-binding oligomerization domain proteins (NODs) and all known toll-like receptors (TLRs) [54, 55]. Binding of microbially-derived and other immunoactive ligands (e.g., oxysterols) to these receptors results in signalling through a variety of adapter proteins and pathways that can culminate in the activation of profibroinflammatory transcription factors and ultimately hepatobiliary fibrosis and inflammation [24,56]. As mentioned before, however, the key PAMPs involved in activating such pathways in PSC have yet to be delineated, and it remains unknown whether they elicit disease due to increased abundance, abnormal moieties/epitopes (e.g., of noncommensal, pathogenic bacteria), exaggerated host responses, or a combination.

Several intriguing observations have been recently made in this regard. The first is that cultured cholangiocytes isolated from PSC liver (as well as peripheral blood mononuclear cells [57]) have been shown to exhibit persistent hypersensitivity (i.e., impaired immune tolerance) to pathogen recognition receptor agonists (e.g., LPS) [58]. In addition, increased TLR and NOD protein expression as well as activation of the MyD88/IRAK adapter protein signalling complex in PSC cholangiocytes have been described [58]. Of note, circulating antibiliary epithelial cell antibodies, an area of research that has been perhaps incompletely explored in the pathogenesis of PSC, may account for the induction of increased TLR expression in PSC cholangiocytes [50]. The second intriguing observation is that not only do patients with PSC exhibit bacterobilia [28] and detectable levels of 16s ribosomal ribonucleic acid (rRNA) in bile $[59,60]$, but also cholangiocytes in PSC liver sections (but not normal livers) have been shown to accumulate LPS [61], which is secreted into bile in a bioactive form $[62,63]$. It should be noted, though, that it remains unknown to what extent bacterobilia or biliary 16s rRNA is the result of previous biliary interventions (e.g., endoscopic retrograde cholangiography) that occurred after PSC had already developed. The third observation is that genome wide association studies have found new PSC risk loci (aside from the human leukocyte antigen complex) related to immunoregulation and immune-mediated disease $[64,65]$. One such example is fucosyltransferase-2, which has been shown to influence the microbiota, affect susceptibility to microbial infection, and be associated with IBD (specifically Crohn's disease) [6567]. More translational studies are needed to determine the effects of both PAMPs and immunogenetic susceptibility on cholangiocyte activation, signaling, and their bearing on PSC pathogenesis.

\section{Clinical Experience with Oral Antibacterial Agents in PSC}

Since the publication of the initial case series of antibiotics in PSC in 1959 (at that time referred to as "chronic pericholangitis") [36], a number of studies of antibiotics in PSC have been published, the majority being within the past 10 years $[2,68]$. Three of these were prospective clinical trials (Table 1(a)): in the first of these three, Färkkilä et al. [34] recruited 80 patients and randomized them to 36 months of treatment with UDCA $(15 \mathrm{mg} / \mathrm{kg} /$ day $)$ plus metronidazole $(n=39)$ or UDCA alone $(n=41)$ in a double blind manner; the authors found a significant improvement in serum alkaline phosphatase (ALK), Mayo PSC risk score, and histologic stage and grade as well as a trend toward less cholangiographic progression in the UDCA plus metronidazole group after 36 months of treatment [34]. In the second clinical trial, Silveira et al. [35] conducted an open label pilot study wherein 16 patients with PSC were treated with minocycline for one year; although a quarter of patients withdrew from the study (majority due to adverse effects), those who continued minocycline treatment experienced a significant reduction in serum ALK and a trend toward a significant reduction in aspartate aminotransferase and Mayo PSC risk score. In the third and most recent clinical trial, Tabibian et al. [25] conducted a phase II, double blind, randomized pilot study of vancomycin and metronidazole. Thirty-five patients with PSC were randomized into 4 groups: low-dose vancomycin, high-dose vancomycin, low-dose metronidazole, or highdose metronidazole. Although individual responses were variable, a significant decrease in ALK at 12 weeks (the primary endpoint) was evident in the low- and high-dose vancomycin groups; furthermore, 2 patients in the lowdose vancomycin group experienced normalization of ALK. 
TABLE 1: Previously reported results of antibacterial treatment in primary sclerosing cholangitis.

(a) Clinical trials of antibacterial treatment in primary sclerosing cholangitis

\begin{tabular}{|c|c|c|c|c|c|c|c|}
\hline \multirow{2}{*}{ Drug (reference) } & \multirow{2}{*}{ Year } & \multirow{2}{*}{$n$} & \multirow{2}{*}{ Antibiotic dose } & \multirow{2}{*}{ Months of therapy } & \multicolumn{3}{|c|}{ Change after therapy } \\
\hline & & & & & ALK & AST & ALT \\
\hline Metronidazole (+UDCA) [34] & 2004 & 39 & $600-800 \mathrm{mg} /$ day & 36 & $-52.4 \%$ & $-41.0 \%$ & $-67.9 \%$ \\
\hline Minocycline [35] & 2009 & 16 & $200 \mathrm{mg} /$ day & 12 & $-19.7 \%$ & $-2.8 \%$ & NA \\
\hline \multirow{2}{*}{ Vancomycin or metronidazole [25] } & \multirow{2}{*}{2013} & 18 & Vancomycin 125 or $250 \mathrm{mg}$ qid & 3 & $-42 \%$ & $-22 \%$ & NA \\
\hline & & 17 & Metronidazole 250 or $500 \mathrm{mg}$ tid & 3 & $-10 \%$ & $-9 \%$ & NA \\
\hline
\end{tabular}

(b) Case series and reports of antibacterial treatment in primary sclerosing cholangitis

\begin{tabular}{|c|c|c|c|c|c|c|c|}
\hline \multirow{2}{*}{ Drug (reference) } & \multirow{2}{*}{ Year } & \multirow{2}{*}{$n$} & \multirow{2}{*}{ Antibiotic dose } & \multirow{2}{*}{ Months of therapy } & \multicolumn{3}{|c|}{ Change after therapy } \\
\hline & & & & & ALK & AST & ALT \\
\hline Tetracycline $[36]^{*}$ & 1959 & 5 & $500 \mathrm{mg} /$ day & $1-10$ & $-45 \%$ & $-60 \%$ & $-45 \%$ \\
\hline Tetracycline $[27]^{\dagger}$ & 1965 & 5 & $500 \mathrm{mg} /$ day & 48 (mean) & $-21 \%$ & NA & NA \\
\hline Metronidazole [37] & 1983 & 1 & $800 \mathrm{mg} /$ day & 0.25 & $\mathrm{NA}^{\text {抹 }}$ & $N A^{\ddagger \ddagger}$ & $\mathrm{NA}^{\ddagger \ddagger}$ \\
\hline Sulfasalazine (+UDCA) $[38]^{\dagger \dagger}$ & 1998 & $2^{\ddagger}$ & - & $\begin{array}{c}30 \text { and } \\
45\end{array}$ & $\begin{array}{l}-79 \% \\
-35 \%\end{array}$ & $\begin{array}{l}-38 \% \\
-87 \%\end{array}$ & $\begin{array}{l}-70 \% \\
-95 \%\end{array}$ \\
\hline Vancomycin [39] & 1998 & $3^{\ddagger}$ & 375-1000 mg/day & 9 (mean) & NA & NA & $-89 \%$ \\
\hline Sulfasalazine (+UDCA) [40] & 2002 & 1 & $50 \mathrm{mg} / \mathrm{kg} /$ day & 37 & NA & NA & $-92 \%$ \\
\hline Sulfasalazine [41] & 2006 & 1 & $2-4.5 \mathrm{~g} /$ day & 24 & $-74 \%$ & NA & $-84 \%$ \\
\hline Azithromycin (+UDCA) [42] & 2007 & 1 & $500 \mathrm{mg} /$ day, 3 days/week & 5 & $-72 \%$ & $-31 \%$ & $-33 \%$ \\
\hline Vancomycin [43] & 2008 & $14^{\ddagger}$ & $50 \mathrm{mg} / \mathrm{kg} /$ day & $54 \pm 43$ & NA & NA & $-78 \%$ \\
\hline
\end{tabular}

Key: ALK: alkaline phosphatase, AST: aspartate aminotransferase; ALT: alanine aminotransferase, GGT: $\gamma$-glutamyl transpeptidase; tid: three times a day; qid: four times a day; UDCA: ursodeoxycholic acid.

Months of treatment and followup are absolute unless otherwise indicated.

${ }^{*}$ Includes one patient who also received prednisone but was not separable from the other 4 patients.

${ }^{\dagger}$ Does not include two patients who received prednisone.

${ }^{\dagger \dagger}$ Does not include a third patient who also received prednisolone and mizoribine.

${ }^{\ddagger}$ Pediatric patients.

${ }^{\ddagger \ddagger}$ Original case report states there was dramatic improvement in patient's condition, including defervescence, return of appetite, and reduction of serum bilirubin, and after 2 weeks, becoming completely asymptomatic. Six months later, patient returned with clinical worsening, which again responded to metronidazole.

Although patients in all 4 groups experienced significant improvements in at least one of the secondary endpoints (serum total bilirubin, C-reactive protein, Mayo PSC risk score, and pruritus), adverse effects were more frequent in the metronidazole groups. Thus, the authors recommended (low-dose) vancomycin for further investigation, ideally in a larger, longer-term, placebo-controlled trial [25].

Aside from these three clinical trials, there have also been several case series and reports of oral antibacterial therapy in PSC (Table 1(b)) [27, 36-43]. Among the most notable of these is a case series by K. L. Cox and K. M. Cox of three pediatric patients with PSC and IBD who experienced normalization of liver tests and resolution of symptoms with oral vancomycin treatment [39]. In a more recent prospective series from the same group, 14 pediatric patients with PSC and IBD were treated with oral vancomycin for $54 \pm 43$ months [43]; the authors noted normalization or significant improvement in serum liver tests, erythrocyte sedimentation rate, and clinical symptoms in nearly all patients. In addition, when vancomycin treatment was discontinued, there was recurrence of clinical symptoms and an increase in liver enzymes in several patients, and retreatment again resulted in normalization of liver enzymes [43]. Of note, there have also been a case report and a small randomized trial of probiotics in PSC which yielded conflicting results $[69,70]$. More recently, there has also been a case report of post-LT PSC successfully treated with oral vancomycin [71].

Although antibiotic trials thus far have been generally small and few in number, taken collectively, their results are favorable and encourage further studies of antibiotics as a potentially safe, effective, and convenient therapy in PSC.

\section{Conclusions and Future Directions}

The body of basic, translational, and clinical data supporting the PSC microbiota hypothesis continues to grow, and with the ever-evolving developments in molecular, cellular, and bioinformatic techniques, it is likely that more insights will be gained. Until then, and before oral antibiotics can become an established therapy for patients with PSC, the following questions and considerations remain.

(1) What is the relative contribution of abnormalities in (i) the number or type of microbially-derived molecules as compared to (ii) the host response (i.e., immunogenetic susceptibility)? 
(2) What is the mechanism of potential therapeutic action of antibacterial agents on PSC? Is it, for example, related to (i) a direct effect on bacterial (and/or other microbial) load or diversity, (ii) secondary changes in the type or amount of bacterial components or metabolites (e.g., LPS and secondary bile acids, resp.) in the gut and/or in the enterohepatic circulation, or (iii) nonantimicrobial effects, for example, anti-inflammatory or immunoregulatory effects, such as those ascribed to minocycline and vancomycin, respectively [35, 72]?

(3) Which PSC patients benefit most from antibiotic therapy, and what are the relevant modifiers (e.g., IBD status, age, and stage)? [2]

(4) What antibiotic and dosing regimen (e.g., daily versus interrupted/alternating) will theoretically provide the most therapeutic effects while minimizing adverse effects such as antibiotic resistance?

(5) Is it time for, and who will design, conduct, and fund, a larger, longer, randomized (i.e., phase II/III) clinical trial of antibacterial therapy in PSC?

\section{Conflict of Interests}

The authors declare that they have no conflict of interests.

\section{References}

[1] A. Gupta and C. L. Bowlus, "Primary sclerosing cholangitis: etiopathogenesis and clinical management," Frontiers in Bioscience, vol. 4, pp. 1683-1705, 2012.

[2] J. H. Tabibian and K. D. Lindor, "Primary sclerosing cholangitis: a review and update on therapeutic developments," Expert Review of Gastroenterology \& Hepatology, vol. 7, pp. 103-114, 2013.

[3] K. Bambha, W. R. Kim, J. Talwalkar et al., "Incidence, clinical spectrum, and outcomes of primary sclerosing cholangitis in a United States community," Gastroenterology, vol. 125, no. 5, pp. 1364-1369, 2003.

[4] G. G. Kaplan, K. B. Laupland, D. Butzner, S. J. Urbanski, and S. S. Lee, "The burden of large and small duct primary sclerosing cholangitis in adults and children: a population-based analysis," American Journal of Gastroenterology, vol. 102, no. 5, pp. 10421049, 2007.

[5] J. H. Tabibian and K. D. Lindor, "Challenges of cholangiocarcinoma detection in patients with primary sclerosing cholangitis," Journal of Analytical Oncology, vol. 1, pp. 50-55, 2012.

[6] R. H. Wiesner, P. M. Grambsch, E. R. Dickson et al., "Primary sclerosing cholangitis: natural history, prognostic factors and survival analysis," Hepatology, vol. 10, no. 4, pp. 430-436, 1989.

[7] R. Chapman, J. Fevery, A. Kalloo et al., "Diagnosis and management of primary sclerosing cholangitis," Hepatology, vol. 51, no. 2, pp. 660-678, 2010.

[8] M. H. Imam, E. Sinakos, A. A. Gossard et al., "High-dose ursodeoxycholic acid increases risk of adverse outcomes in patients with early stage primary sclerosing cholangitis," Alimentary Pharmacology and Therapeutics, vol. 34, no. 10, pp. 1185-1192, 2011.
[9] T. H. Karlsen, E. Schrumpf, and K. M. Boberg, "Update on primary sclerosing cholangitis," Digestive and Liver Disease, vol. 42, no. 6, pp. 390-400, 2010.

[10] K. Bjøro, B. Brandsaerter, A. Foss, and E. Schrumpf, "Liver transplantation in primary sclerosing cholangitis," Seminars in Liver Disease, vol. 26, no. 1, pp. 69-79, 2006.

[11] E. Alabraba, P. Nightingale, B. Gunson et al., "A re-evaluation of the risk factors for the recurrence of primary sclerosing cholangitis in liver allografts," Liver Transplantation, vol. 15, no. 3, pp. 330-340, 2009.

[12] I. W. Graziadei, "Live donor liver transplantation for primary sclerosing cholangitis: is disease recurrence increased?" Current Opinion in Gastroenterology, vol. 27, no. 3, pp. 301-305, 2011.

[13] C. Landaverde, V. Ng, A. Sato, J. Tabibian, F. Durazo, and R. Busuttil, "De-novo cholangiocarcinoma in native common bile duct remnant following OLT for primary sclerosing cholangitis," Annals of Hepatology, vol. 8, no. 4, pp. 379-383, 2009.

[14] J. H. Tabibian, S. P. O'Hara, and N. F. Larusso, "Primary sclerosing cholangitis: the Gut-Liver axis," Clinical Gastroenterology and Hepatology, vol. 10, pp. 819-820, 2012.

[15] S. I. Schwartz and W. A. Dale, "Primary sclerosing cholangitis; review and report of six cases," A.M.A. Archives of Surgery, vol. 77, no. 3, pp. 439-451, 1958.

[16] M. E. Thorpe, P. J. Scheuer, and S. Sherlock, "Primary sclerosing cholangitis, the biliary tree, and ulcerative colitis," Gut, vol. 8, no. 5, pp. 435-448, 1967.

[17] E. V. Loftus Jr., G. C. Harewood, C. G. Loftus et al., "PSC-IBD: a unique form of inflammatory bowel disease associated with primary sclerosing cholangitis," Gut, vol. 54, no. 1, pp. 91-96, 2005.

[18] H. Okada, M. Mizuno, K. Yamamoto, and T. Tsuji, "Primary sclerosing cholangitis in Japanese patients: association with inflammatory bowel disease," Acta Medica Okayama, vol. 50, no. 5, pp. 227-235, 1996.

[19] K. Welcker, A. Martin, O. Kölle, M. Siebeck, and M. Gross, "Increased intestinal permeability in patients with inflammatory bowel disease," European Journal of Medical Research, vol. 9, no. 10, pp. 456-460, 2004.

[20] K. D. Katz, D. Hollander, C. M. Vadheim et al., "Intestinal permeability in patients with Crohn's disease and their healthy relatives," Gastroenterology, vol. 97, no. 4, pp. 927-931, 1989.

[21] S. Buhner, C. Buning, J. Genschel et al., "Genetic basis for increased intestinal permeability in families with Crohn's disease: role of CARD15 3020insC mutation?" Gut, vol. 55, no. 3, pp. 342-347, 2006.

[22] J. H. Tabibian, A. I. Masyuk, T. V. Masyuk, S. P. O’Hara, and N. F. LaRusso, "Cholangiocyte physiology," Comprehensive Physiology, vol. 3, pp. 541-565, 2013.

[23] C. A. O’Mahony and J. M. Vierling, "Etiopathogenesis of primary sclerosing cholangitis," Seminars in Liver Disease, vol. 26, no. 1, pp. 3-21, 2006.

[24] S. P. O'Hara, J. H. Tabibian, P. L. Splinter et al., "The dynamic biliary epithelia: molecules, pathways, and disease," Journal of Hepatology, vol. 58, pp. 575-582, 2013.

[25] J. H. Tabibian, E. Weeding, R. A. Jorgensen et al., "Randomised clinical trial: vancomycin or metronidazole in patients with primary sclerosing cholangitis-A Pilot Study," Alimentary Pharmacology \& Therapeutics, vol. 37, pp. 604-612, 2013.

[26] E. Björnsson, A. Cederborg, A. Åkvist, M. Simren, P.-O. Stotzer, and I. Bjarnason, "Intestinal permeability and bacterial growth of the small bowel in patients with primary sclerosing 
cholangitis," Scandinavian Journal of Gastroenterology, vol. 40, no. 9, pp. 1090-1094, 2005.

[27] S. P. Mistilis, A. P. Skyring, and S. J. Goulston, "Effect of longterm tetracycline therapy, steroid therapy and colectomy in pericholangitis associated with ulcerative colitis," Australasian Annals of Medicine, vol. 14, no. 4, pp. 286-294, 1965.

[28] J. Pohl, A. Ring, W. Stremmel, and A. Stiehl, "The role of dominant stenoses in bacterial infections of bile ducts in primary sclerosing cholangitis," European Journal of Gastroenterology and Hepatology, vol. 18, no. 1, pp. 69-74, 2006.

[29] H. Duboc, S. Rajca, D. Rainteau et al., "Connecting dysbiosis, bile-acid dysmetabolism and gut inflammation in inflammatory bowel diseases," Gut, vol. 62, no. 4, pp. 531-539, 2013.

[30] A. W. DuPont and H. L. DuPont, “The intestinal microbiota and chronic disorders of the gut," Nature Reviews Gastroenterology \& Hepatology, vol. 8, pp. 523-531, 2011.

[31] J. C. Clemente, L. K. Ursell, L. W. Parfrey, and R. Knight, “The impact of the gut microbiota on human health: an integrative view," Cell, vol. 148, no. 6, pp. 1258-1270, 2012.

[32] T. J. Weismüller, J. Wedemeyer, S. Kubicka, C. P. Strassburg, and M. P. Manns, "The challenges in primary sclerosing cholangitis - aetiopathogenesis, autoimmunity, management and malignancy," Journal of Hepatology, vol. 48, no. 1, pp. S38-S57, 2008.

[33] J. Worthington, S. Cullen, and R. Chapman, "Immunopathogenesis of primary sclerosing cholangitis," Clinical Reviews in Allergy and Immunology, vol. 28, no. 2, pp. 93-103, 2005.

[34] M. Färkkilä, A.-L. Karvonen, H. Nurmi et al., "Metronidazole and ursodeoxycholic acid for primary sclerosing cholangitis: a randomized placebo-controlled trial," Hepatology, vol. 40, no. 6, pp. 1379-1386, 2004.

[35] M. G. Silveira, N. J. Torok, A. A. Gossard et al., "Minocycline in the treatment of patients with primary sclerosing cholangitis: results of a pilot study," American Journal of Gastroenterology, vol. 104, no. 1, pp. 83-88, 2009.

[36] J. G. Rankin, R. W. Boden, S. J. M. Goulston, and W. Morrow, "The liver in ulcerative colitis; treatment of pericholangitis with tetracycline," The Lancet, vol. 274, no. 7112, pp. 1110-1112, 1959.

[37] K. K. Mathew, "Metronidazole in primary cholangitis," Journal of the Indian Medical Association, vol. 80, no. 2, p. 31, 1983.

[38] K. Kozaiwa, H. Tajiri, A. Sawada et al., "Case report: three paediatric cases of primary sclerosing cholangitis treated with ursodeoxycholic acid and sulphasalazine," Journal of Gastroenterology and Hepatology, vol. 13, no. 8, pp. 825-829, 1998.

[39] K. L. Cox and K. M. Cox, "Oral vancomycin: treatment of primary sclerosing cholangitis in children with inflammatory bowel disease," Journal of Pediatric Gastroenterology and Nutrition, vol. 27, no. 5, pp. 580-583, 1998.

[40] T. Broccoletti, E. Ciccimarra, M. Spaziano et al., "Refractory primary sclerosing cholangitis becoming responsive after sulphasalazine treatment of an underlying silent colitis," Italian Journal of Pediatrics, vol. 28, no. 6, pp. 515-517, 2002.

[41] S. Tada, H. Ebinuma, H. Saito, and T. Hibi, "Therapeutic benefit of sulfasalazine for patients with primary sclerosing cholangitis," Journal of Gastroenterology, vol. 41, no. 4, pp. 388389, 2006.

[42] A. L. Boner, D. Peroni, A. Bodini, G. Delaini, and G. Piacentini, "Azithromycin may reduce cholestasis in primary sclerosing cholangitis: a case report and serendipitous observation," International Journal of Immunopathology and Pharmacology, vol. 20, no. 4, pp. 847-849, 2007.
[43] Y. K. Davies, K. M. Cox, B. A. Abdullah, A. Safta, A. B. Terry, and K. L. Cox, "Long-term treatment of primary sclerosing cholangitis in children with oral vancomycin: an immunomodulating antibiotic," Journal of Pediatric Gastroenterology and Nutrition, vol. 47, no. 1, pp. 61-67, 2008.

[44] J. H. Tabibian, S. I. Macura, S. P. O'Hara et al., "Microcomputed tomography and nuclear magnetic resonance imaging for noninvasive, live-mouse cholangiography," Laboratory Investigation, vol. 93, pp. 733-743, 2013.

[45] S. N. Lichtman, J. Keku, R. L. Clark, J. H. Schwab, and R. B. Sartor, "Biliary tract disease in rats with experimental small bowel bacterial overgrowth," Hepatology, vol. 13, no. 4, pp. 766772, 1991.

[46] S. N. Lichtman, E. E. Okoruwa, J. Keku, J. H. Schwab, and R. B. Sartor, "Degradation of endogenous bacterial cell wall polymers by the muralytic enzyme mutanolysin prevents hepatobiliary injury in genetically susceptible rats with experimental intestinal bacterial overgrowth," Journal of Clinical Investigation, vol. 90, no. 4, pp. 1313-1322, 1992.

[47] S. N. Lichtman, J. Wang, and R. L. Clark, "A microcholangiographic study of liver disease models in rats," Academic Radiology, vol. 2, no. 6, pp. 515-521, 1995.

[48] S. Yamada, M. Ishii, L. S. Liang, T. Yamamoto, and T. Toyota, "Small duct cholangitis induced by N-formyl L-methionine Lleucine L-tyrosine in rats," Journal of Gastroenterology, vol. 29, no. 5, pp. 631-636, 1994.

[49] I. Haruta, K. Kikuchi, E. Hashimoto et al., "Long-term bacterial exposure can trigger nonsuppurative destructive cholangitis associated with multifocal epithelial inflammation," Laboratory Investigation, vol. 90, no. 4, pp. 577-588, 2010.

[50] A. Karrar, U. Broomé, T. Södergren et al., "Biliary epithelial cell antibodies link adaptive and innate immune responses in primary sclerosing cholangitis," Gastroenterology, vol. 132, no. 4, pp. 1504-1514, 2007.

[51] M. J. Pollheimer, M. Trauner, and P. Fickert, "Will we ever model PSC? 'it's hard to be a PSC model!'” Clinics and Research in Hepatology and Gastroenterology, vol. 35, no. 12, pp. 792-804, 2011.

[52] S. P. O’Hara, P. L. Splinter, C. E. Trussoni, G. B. Gajdos, P. N. Lineswala, and N. F. LaRusso, "Cholangiocyte N-Ras protein mediates lipopolysaccharide-induced interleukin 6 secretion and proliferation," Journal of Biological Chemistry, vol. 286, no. 35, pp. 30352-30360, 2011.

[53] K. Harada and Y. Nakanuma, "Cholangiopathy with respect to biliary innate immunity," International Journal of Hepatology, vol. 2012, Article ID 793569, 10 pages, 2012.

[54] X.-M. Chen, S. P. O’Hara, J. B. Nelson et al., "Multiple TLRs are expressed in human cholangiocytes and mediate host epithelial defense responses to Cryptosporidium parvum via activation of NF- $\kappa$ B," Journal of Immunology, vol. 175, no. 11, pp. 7447-7456, 2005.

[55] T. Yokoyama, A. Komori, M. Nakamura et al., "Human intrahepatic biliary epithelial cells function in innate immunity by producing IL- 6 and IL- 8 via the TLR4-NF- $\kappa$ B and -MAPK signaling pathways," Liver International, vol. 26, no. 4, pp. 467$476,2006$.

[56] X.-M. Chen, S. P. O'Hara, and N. F. LaRusso, "The immunobiology of cholangiocytes," Immunology and Cell Biology, vol. 86, no. 6, pp. 497-505, 2008.

[57] J. Katt, D. Schwinge, T. Schoknecht et al., "Increased th17 response to pathogen stimulation in patients with primary 
sclerosing cholangitis," Hepatology, vol. 58, no. 3, pp. 1084-1093, 2013.

[58] T. Mueller, C. Beutler, A. H. Picó et al., "Enhanced innate immune responsiveness and intolerance to intestinal endotoxins in human biliary epithelial cells contributes to chronic cholangitis," Liver International, vol. 31, no. 10, pp. 1574-1588, 2011.

[59] R. Olsson, E. Björnsson, L. Bäckman et al., "Bile duct bacterial isolates in primary sclerosing cholangitis: a study of explanted livers," Journal of Hepatology, vol. 28, no. 3, pp. 426-432, 1998.

[60] K. Hiramatsu, K. Harada, K. Tsuneyama et al., "Amplification and sequence analysis of partial bacterial 16 S ribosomal RNA gene in gallbladder bile from patients with primary biliary cirrhosis," Journal of Hepatology, vol. 33, no. 1, pp. 9-18, 2000.

[61] K. Sasatomi, K. Noguchi, S. Sakisaka, M. Sata, and K. Tanikawa, "Abnormal accumulation of endotoxin in biliary epithelial cells in primary biliary cirrhosis and primary sclerosing cholangitis," Journal of Hepatology, vol. 29, no. 3, pp. 409-416, 1998.

[62] Y. Mimura, S. Sakisaka, M. Harada, M. Sata, and K. Tanikawa, "Role of hepatocytes in direct clearance of lipopolysaccharide in rats," Gastroenterology, vol. 109, no. 6, pp. 1969-1976, 1995.

[63] T. Osnes, O. Sandstad, V. Skar, and M. Osnes, "Lipopolysaccharides and beta-glucuronidase activity in choledochal bile in relation to choledocholithiasis," Digestion, vol. 58, no. 5, pp. 437443, 1997.

[64] J. Z. Liu, J. R. Hov, T. Folseraas et al., "Dense genotyping of immune-related disease regions identifies nine new risk loci for primary sclerosing cholangitis," Nature Genetics, vol. 45, no. 6 , pp. 670-675, 2013.

[65] T. Folseraas, E. Melum, P. Rausch et al., "Extended analysis of a genome-wide association study in primary sclerosing cholangitis detects multiple novel risk loci," Journal of Hepatology, vol. 57, pp. 366-375, 2012.

[66] P. Rausch, A. Rehman, S. Künzel et al., "Colonic mucosaassociated microbiota is influenced by an interaction of crohn disease and FUT2 (Secretor) genotype," Proceedings of the National Academy of Sciences of the United States of America, vol. 108, no. 47, pp. 19030-19035, 2011.

[67] D. P. B. McGovern, M. R. Jones, K. D. Taylor et al., "Fucosyltransferase 2 (FUT2) non-secretor status is associated with Crohn's disease," Human Molecular Genetics, vol. 19, no. 17, Article ID ddq248, pp. 3468-3476, 2010.

[68] D. A. H. Elfaki and K. D. Lindor, "Antibiotics for the treatment of primary sclerosing cholangitis," American Journal of Therapeutics, vol. 18, no. 3, pp. 261-265, 2011.

[69] M. Shimizu, H. Iwasaki, S. Mase et al., "Successful treatment of primary sclerosing cholangitis with a steroid and a probiotic," Case Reports in Gastroenterology, vol. 6, pp. 249-253, 2012.

[70] F. P. Vleggaar, J. F. Monkelbaan, and K. J. Van Erpecum, "Probiotics in primary sclerosing cholangitis: a randomized placebo-controlled crossover pilot study," European Journal of Gastroenterology and Hepatology, vol. 20, no. 7, pp. 688-692, 2008.

[71] Y. K. Davies, C. J. Tsay, D. V. Caccamo et al., "Successful treatment of recurrent primary sclerosing cholangitis after orthotopic liver transplantation with oral vancomycin," Case Rep Transplant, vol. 2013, Article ID 314292, 5 pages, 2013.

[72] D. N. Abarbanel, S. M. Seki, Y. Davies et al., "Immunomodulatory effect of vancomycin on treg in pediatric inflammatory bowel disease and primary sclerosing cholangitis," Journal of Clinical Immunology, vol. 33, pp. 397-406, 2013. 


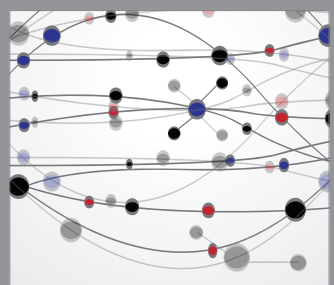

The Scientific World Journal
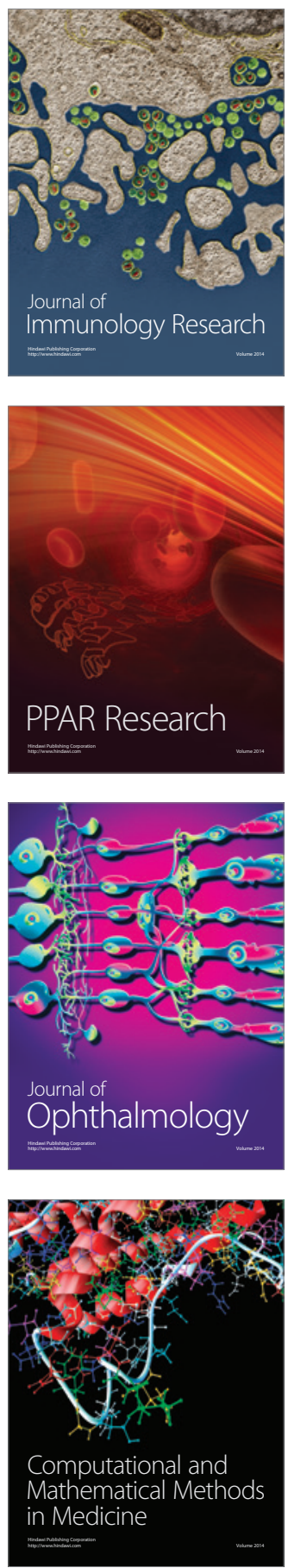

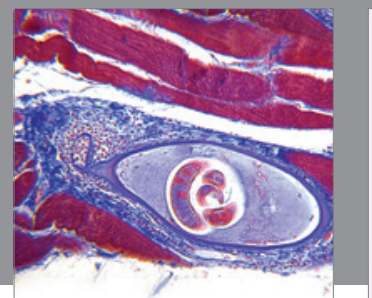

Gastroenterology

Research and Practice
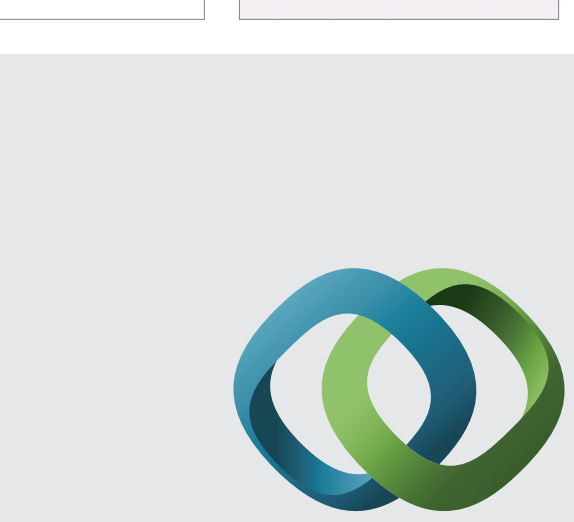

\section{Hindawi}

Submit your manuscripts at

http://www.hindawi.com
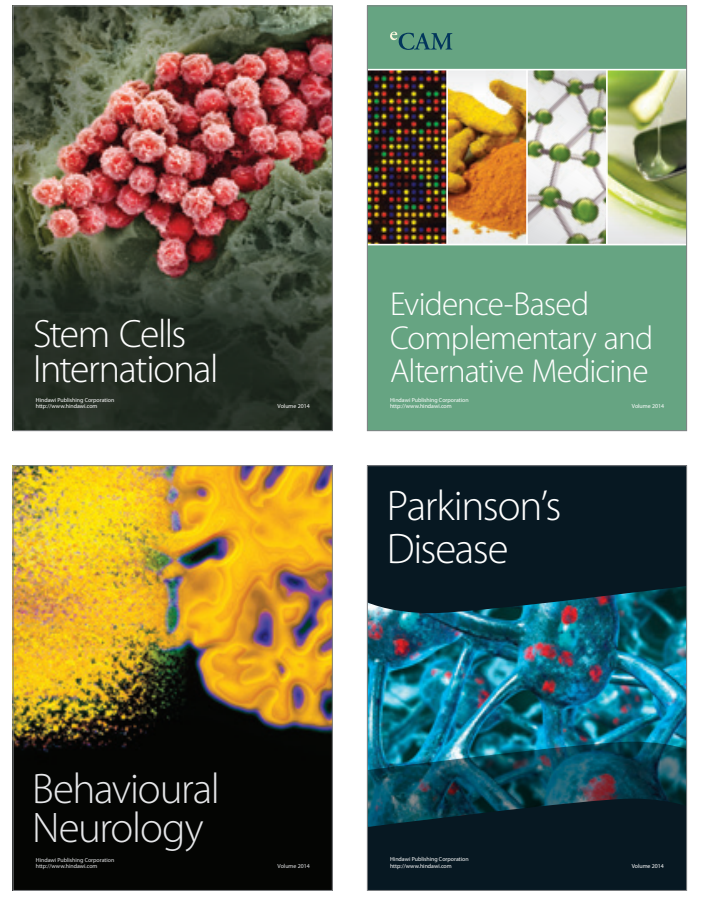
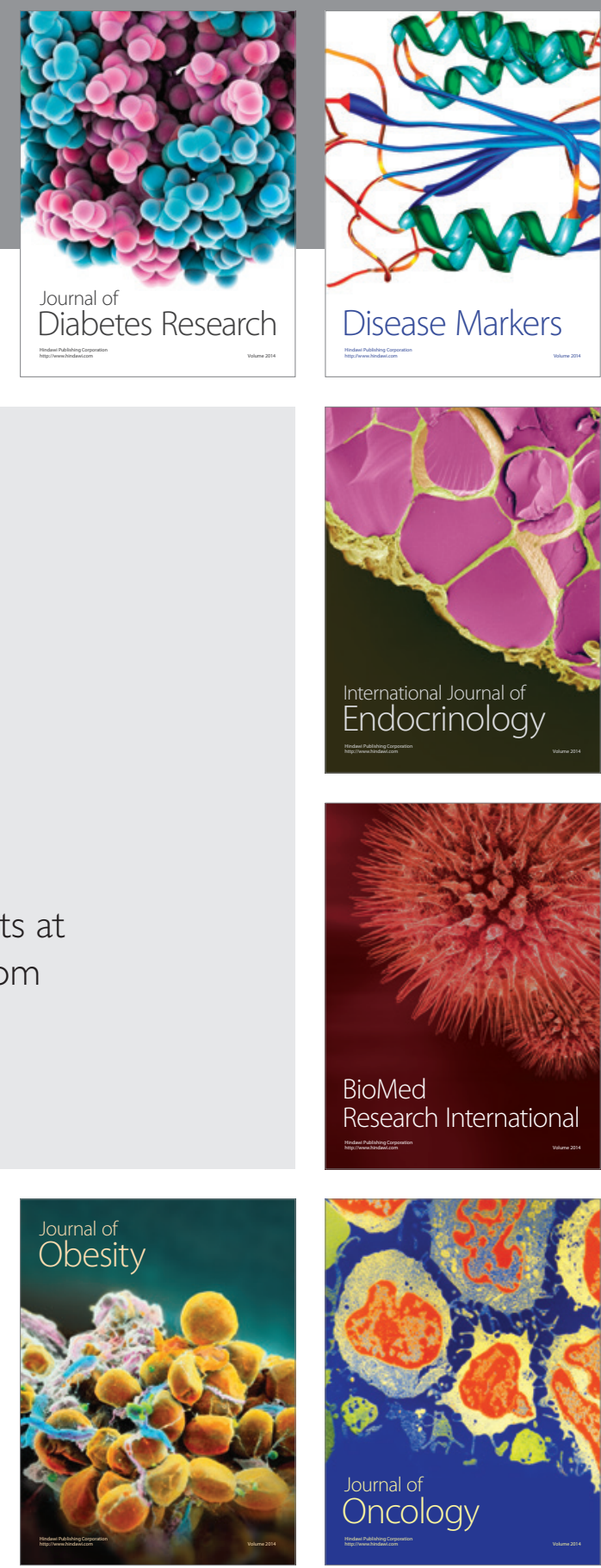

Disease Markers
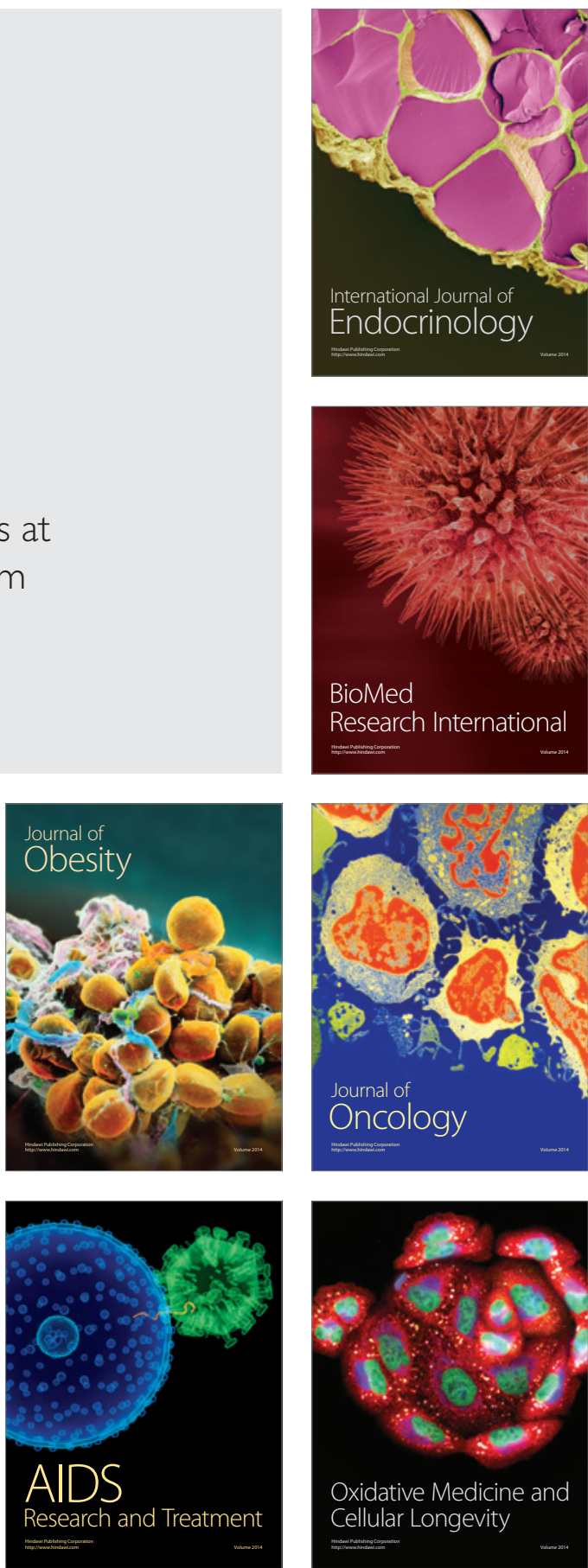